\title{
Solidification, Microstructure, and Mechanical Properties of Mg-Nd-Gd-Zn-Zr Magnesium Alloy with 1.5 Samarium
}

\author{
R. Ahmad ${ }^{* 1}$, A.M.M. Elaswad ${ }^{2}$ Z.M. Sheggaf ${ }^{3}$ \\ ${ }^{1}$ Department of Manufacturing Engineering, Faculty of Mechanical and Manufacturing Engineering, Universiti \\ Tun Hussein Onn Malaysia, Parit Raja,86400 Batu Pahat, Johor, Malaysia \\ ${ }^{2}$ Department of Mechanical Engineering, Al-zintan University, Alzintan Libya \\ ${ }^{3}$ Department of Mechanical Engineering, College of Technical Sciences, Bani Walid, Libya \\ E-mail: roslee@uthm.edu.my
}

Article History: Received: 10 November 2020; Revised: 12 January 2021; Accepted: 27 January 2021; Published online: 05 April 2021

\begin{abstract}
The influence of samarium (Sm) content on the solidification characteristics, microstructure, and mechanical properties of $\mathrm{Mg}-2.8 \mathrm{wt} \% \mathrm{Nd}-1.5 \mathrm{wt} \% \mathrm{Gd}-0.5 \mathrm{wt} \% \mathrm{Zn}-0.5 \mathrm{wt} \% \mathrm{Zr}$ magnesium alloy was studied. The cooling curves and microstructure analysis results showed that $\mathrm{Sm}$ rare earth element refined the grains of the alloys, where the solidification time of $\alpha-\mathrm{Mg}$ phase of decreased as addition of Sm, which reflected to the microstructure of alloy and the grains became refined, also Sm combined with the initial phase of the intermetallic base alloy and crystallized along the grain boundaries. In addition, $\mathrm{Mg}_{41} \mathrm{Sm}_{5}, \mathrm{Mg}_{3} \mathrm{Zn}_{6} \mathrm{Sm}$ and $(\mathrm{Mg}, \mathrm{Zn})_{3} \mathrm{Sm}$ new intermetallic phases were formed as addition of Sm. Both grain refinement and formed intermetallic phases led to the improvement in hardness and tensile strength.

Keywords: Magnesium alloys, rare earth, thermal analysis, microstructure, mechanical properties
\end{abstract}

\section{Introduction}

Reduced weight of products can be attained by many approaches such as redesign, removal of unnecessary parts, reducing thickness and selection of light materials. For such reasons, much effort has been spent on developing lighter materials, such as composites, and $\mathrm{Al}$ and $\mathrm{Mg}$ alloys for vehicles, and aerospace industrials (Ferro, Saccone et al. 2013). Magnesium is the 6th most plentiful component in the world's covering and is the lightest of every single auxiliary metal with a high specific stiffness(Ali, Qiu et al. 2015). The focus on $\mathrm{Mg}-\mathrm{RE}$ (RE such as Sm, Yt, Pr, Gd, etc.) alloys is attributed to the significant strength at the normal and relatively high temperatures, and also because of their practical creep resistance (Easton, Gibson et al. 2018). Recent studies highlighted that some rare earth (RE) metals, such as Yttrium (Y), Neodymium (Nd) and Samarium (Sm) are very effective elements to improve the mechanical properties of $\mathrm{Mg}$ alloys. Mechanical properties of magnesium can be enhanced by adding different contents of element-alloy which results improvements in increased tensile strength, creep resistance, thermal stability, or corrosion resistance. Thermal analysis techniques are performed to investigate the solidification characteristics of metals and their alloys. Recently, in industrial applications, computer-aided cooling curve analysis (CA-CCTA) is common method, and has been successfully applied to several investigations on the solidification sequences of magnesium alloys (Farahany, Bakhsheshi-Rad et al. 2012), (Lotfabadi, Idris et al. 2013). In this paper, the solidification behavior, microstructure, and mechanical properties of $\mathrm{Mg}-\mathrm{Nd}-\mathrm{Gd}-\mathrm{Zn}-\mathrm{Zr}$ magnesium alloy with samarium additions are investigated.

\section{Experimental}

In this paper samarium $(\mathrm{Sm})$ rare earth element with $(1.5 \mathrm{wt} . \%)$ added into the $\mathrm{Mg}-2.8 \mathrm{wt} \% \mathrm{Nd}-1.5 \mathrm{wt} \% \mathrm{Gd}-$ $0.5 \mathrm{wt} \% \mathrm{Zn}-0.5 \mathrm{wt} \% \mathrm{Zr}$ magnesium alloy. The base alloy was melted at a temperature of $750{ }^{\circ} \mathrm{C}$ in an induction furnace using $\mathrm{Ar}$ and $2 \%$ of SF6 mixed gas. The solidification characteristics of cooling curves of the investigated alloys were determined via CA-CCTA, where two K-type thermocouples are used, one of them was placed in the center of the mould and the other one is closed to the wall. The solidified samples were cut from the central section of ingots and then prepared according to the standard of ASTM E3 to be used for metallographic examination. The optical microscope $(\mathrm{OM})$ observed the microstructure of the alloy, and a scanning electron microscope (SEM). The samples of tensile test were produced using the permanent casting process with steel mould, and each casting provided three tensile bars. The bars of final test were cut and machined using a CNC machine according to the standard dimensions of ASTM B557, and the reported values are the average of at least three measurements. Hardness test is performed using Vickers hardness (Hv) on the same samples that are used for microstructure analysis according to the standard of ASTM E92, with the $5 \mathrm{Kg}$, applied load and 10-second load holding time, and the reported values of hardness are the average of seven readings for any sample.

\section{Results and Discussion}




\subsection{Solidification Characteristics}

Fig. 1 shows the cooling curves that extracted during solidification process of the investigated alloys.
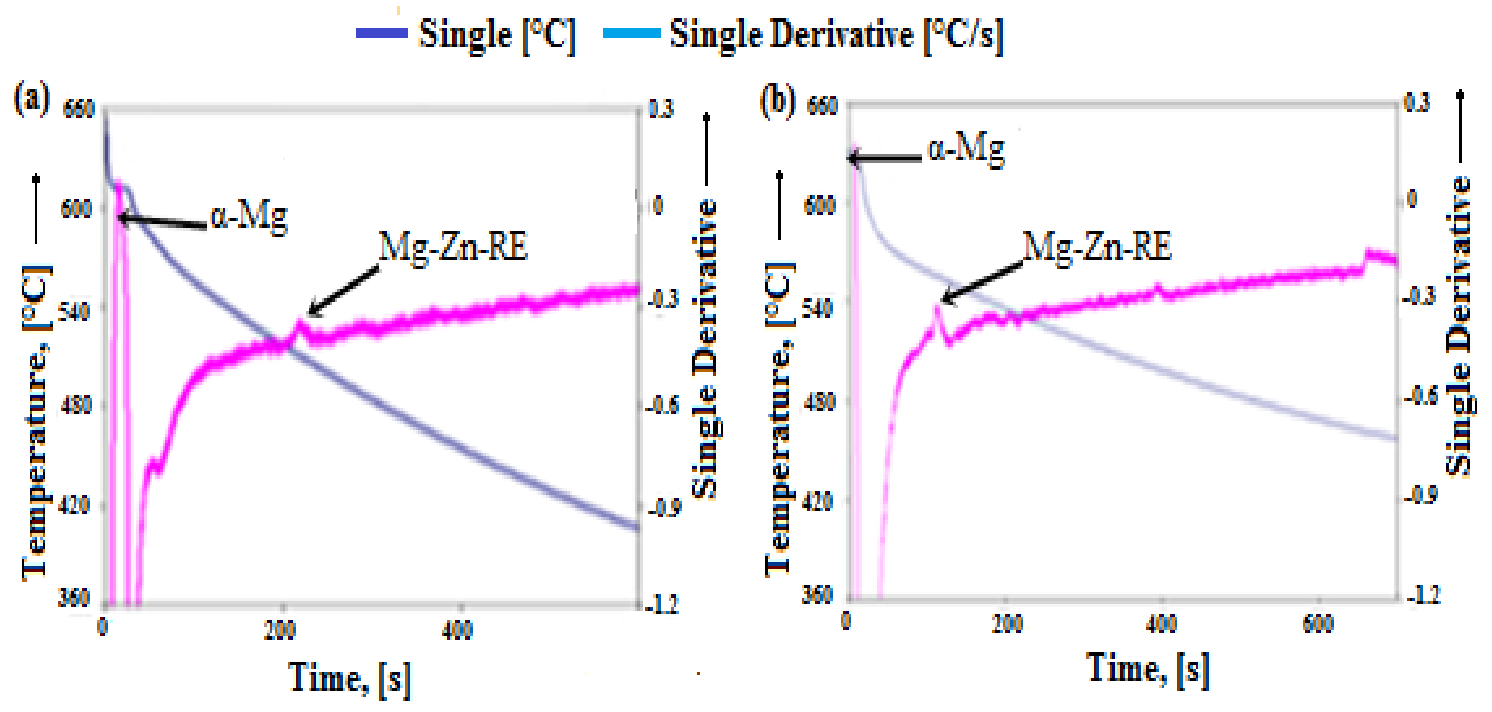

Figure 1. The cooling curves of. (a) Base alloy (b) Treated with 1.5 wt. \% Sm

The nucleation and growth of the primary $\alpha-\mathrm{Mg}$ phase are the first stage of solidification process of $\mathrm{Mg}$ alloys, which followed by other formed phases containing the alloying elements. From the first derivative of cooling curves, the main characteristic parameters of $\alpha-\mathrm{Mg}$ phase have been determined, including nucleation

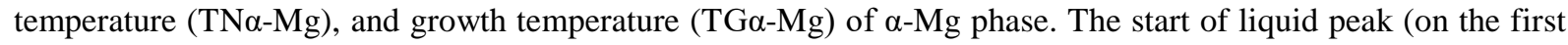
derivative curve) is denoted by temperature $(\mathrm{TN} \alpha-\mathrm{Mg})$, which is considered as the beginning of the solidification (Song, Wu et al. 2014).

At $635.9{ }^{\circ} \mathrm{C}, \alpha-\mathrm{Mg}$ phase of base alloy is formed (TG $\alpha-\mathrm{Mg}$ ), and as temperature reached $645.8{ }^{\circ} \mathrm{C}$, the solidification begins (TN $\alpha-\mathrm{Mg}$ ). The solidification temperature started in $\mathrm{Mg}-10 \mathrm{Gd}-3 \mathrm{Y}-0.4 \mathrm{Zr}$ alloy at $640.2^{\circ} \mathrm{C}$ (Song, $\mathrm{Wu}$ et al. 2015), and $\alpha-\mathrm{Mg}$ phases of the as-cast $\mathrm{Mg}-4 \mathrm{Sm}-4 \mathrm{Zn}-0.5 \mathrm{Zr}$ alloy formed at $642{ }^{\circ} \mathrm{C}$ (Che, Cai et al. 2017). The primary stable dendrites start to solidify from the melt at nucleation temperature $(\mathrm{TN} \alpha-\mathrm{Mg})$, which decreased to $641.3{ }^{\circ} \mathrm{C}$ as $1.5 \mathrm{wt}$. \% of Sm added due to forming of third phase which detected via XRD. The above results showed that a part of Sm dissolves into $\alpha-\mathrm{Mg}$ matrix during the solidification of the alloy. Moreover, high melting point compounds Mg41Sm5 act as a bar to the growth of $\alpha$-Mg grain, which lead to decreasing the nucleation temperature of $\alpha-\mathrm{Mg}$ phase(Zhou, Li et al. 2015). The solidus temperature decrements as result of decrease the nucleation temperature of $\alpha-\mathrm{Mg}$ phase and simultaneously widened the solidification range (Dobrzański, Król et al. 2010). Addition of Sm, caused to segregate the second phase gradually, and reduce the nucleation particles of $\alpha-\mathrm{Mg}(\mathrm{Chen}$, Jin et al. 2015). Furthermore, forming a new intermetallic compound (Mg3Zn6Sm ternary phase) which detected by XRD at the grain boundaries of microstructure of treated alloy that led to decrease of the nucleation and growth temperature of primary magnesium dendrite. Addition of $\mathrm{Sm}$ results in it enrichment into front of the solidification interface, then the enrichment $\mathrm{Sm}$ effectively prevents the other alloy elements from diffusing to the matrix $\alpha-\mathrm{Mg}$, which led to significant increase in quantity of the eutectic phases (Zhang, Huang et al. 2017).

As addition of Sm, the solidification time $\alpha-\mathrm{Mg}$ phase $(\Delta \mathrm{t} \alpha-\mathrm{Mg}=\mathrm{tG} \alpha-\mathrm{Mg}-\mathrm{tN} \alpha-\mathrm{Mg})$ decreased, which leads to grain refinement of the alloys. It has been reported that addition of rare earth (RE) into $\mathrm{Mg}-\mathrm{Zn}$ alloys had an important effect on changing the solid solubility of the $\mathrm{Zn}$ in the matrix as a result of decrement in the solidus curve, which shortened the time of nucleation and reduced the grain size (Li, Du et al. 2012, Singh, Srinivasan et al. 2014). Mg-Zn-RE intermetallic compound formation was the last stage of solidification process, and the growth temperature (TGMg-Zn-RE) and growth time (tGMg-Zn-RE) have been determined the temperature and time of end of solidification (solidus temperature and time), (Ts\&ts) were found too. As a result, the growth temperature of $\mathrm{Mg}-\mathrm{Zn}$ - RE phase of base alloy was $526.8{ }^{\circ} \mathrm{C}$, which decreased to $526{ }^{\circ} \mathrm{C}$ with addition of $\mathrm{Sm}$. The results of solidus temperature (temperature of solidification end) showed almost similar behavior with growth temperatures of $\mathrm{Mg}-\mathrm{Zn}$-RE phase, where obtained at $521.7^{\circ} \mathrm{C}$ with addition of $\mathrm{Sm}$ compared with 521.4 ${ }^{\circ} \mathrm{C}$ for the alloy without treated. The solidification temperature (solidification range, $\Delta \mathrm{T}=\mathrm{TN} \alpha-\mathrm{Mg}-\mathrm{Ts}$ ), and frozen time (solidification time, $\Delta \mathrm{t}=\mathrm{t}_{\mathrm{s}}-\mathrm{t}_{\mathrm{N}}{ }^{\alpha-\mathrm{Mg}}$ ) of the alloys have been obtained as well. The frozen time of base 
alloy was obtained as $220.56 \mathrm{~s}$, which decreased significantly to $173.19 \mathrm{~s}$ with addition of $1.5 \mathrm{wt}$ \% of Sm. $\mathrm{Mg}$ and Sm have almost similar atomic radius (Magnesium atom- $0.16 \mathrm{~nm}$, Samarium atom- $0.179 \mathrm{~nm}$ ), and according to the metallographic theory, Sm element usually acts as heterogeneous crystalline core which lead to the refinement of grains, and shortens the nucleation (Xu, Feng et al. 2017). The solidification temperatures results showed a high change, which receded from 124.8 to $119.6{ }^{\circ} \mathrm{C}$ as the base alloy treated with $\mathrm{Sm}$. The solidification temperature clearly decreased and diffusion of $\mathrm{Sm}$ atoms become harder, nucleation of new phase formed at low temperature thereby widen the solidification temperature and solidification time in the present investigated alloy.

\subsection{Microstructure Analysis}

Optical micrographs are shown in Figure 2. As a result, the microstructures of alloys consist of $\alpha$-Mg matrix and second phase crystallized along the grain boundaries, which showed a kind of massive morphology with dark contrast. In addition, microstructure of base alloy appears to have a greater density of fine second phase particles within the grain as well as a few coarse precipitates at the grain boundaries.

(a)

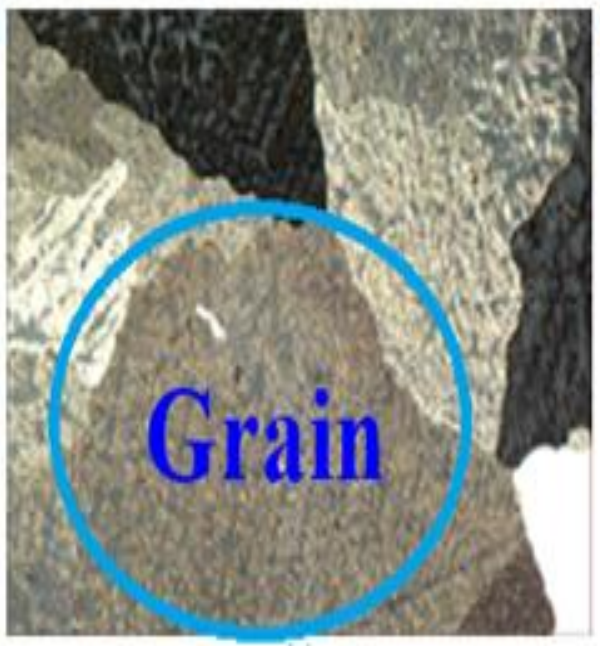

(b)

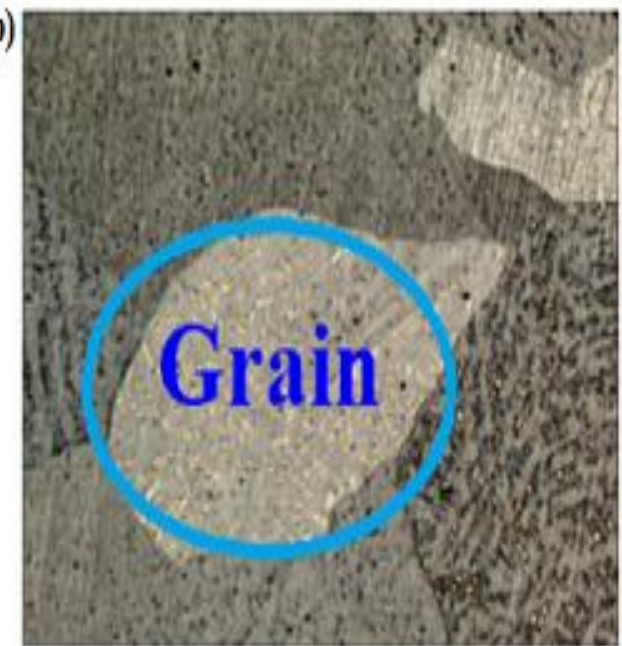

Figure 2. Microstructures image of: (a) base alloy and (b) base alloy treated with 1.5 wt. \% (x50)

The grain sizes of alloys ( 0 and 1.5) wt. \% Sm are $383.84 \mu \mathrm{m}$ and $223.66 \mu \mathrm{m}$, respectively, this result showed that $\mathrm{Sm}$ addition demonstrate to be beneficial to refining the grain size of investigated alloy. The reduction in grain size occurred due to the reduced solidification time $(\Delta \mathrm{t} \alpha-\mathrm{Mg})$, and heterogeneous nucleate particles, where Sm rare earth element restricted the growth of grains (ZHANG, HUANG et al. 2017). It has been reported that the grains of $\mathrm{Mg}$ alloys microstructure refined due to heterogeneous nucleation of $\alpha$ - $\mathrm{Mg}$ primary phase on spherical particles and suppressed grain growing process (Guan, Meng et al. 2019).

The volume fraction of the intermetallic Mg-Zn-RE phase increased obviously as addition of Sm, which obtained $28.67 \%$ and $35.16 \%$ for base alloy and alloy treated with 1.5 wt. \% of Sm respectively. Results of previous studies showed that the volume fraction of intermetallic phases increased as increase Sm content. Also, the microstructure obtained from adding Sm into $\mathrm{Mg}$ alloys mainly consists of $\alpha-\mathrm{Mg}$ matrix and second phase (such as $\mathrm{Mg} 41 \mathrm{Sm5}$ ) phase witch distributed at the grain boundaries, and the amount of the second phase increased with increase Sm content. (Sun, Hu et al. 2015, Zhang, Huang et al. 2017, Guan, Li et al. 2018).

As shown from SEM micrographs, the microstructure of untreated alloy consists of $\alpha-\mathrm{Mg}$ grains marked A, surrounded by second phase crystallized along the grain boundaries as a kind of massive morphology (Figure 3a) marked B. Moreover, as a result of EDS spectrum for regions A and B, the intermetallic secondary phase was composed of magnesium, zinc, gadolinium and neodymium, (Marked B) and the matrix contains magnesium and a small amount of zirconium, (Marked A). SEM micrographs of the alloy treated with Sm showed that its microstructure was composed of primary $\alpha-\mathrm{Mg}$ phase and intermetallic eutectic phase distributed along grain boundaries as well as a few isolated particles inside the grains also a third phase coexisted with the secondary phase. Two different regions and morphology for intermetallic compounds, which crystallized along the grain boundaries; light grey region (Figure 3-b marked D) and dark grey region (Figure 3-b marked C). The light grey region consists of $\mathrm{Mg}-\mathrm{Zn}-\mathrm{Nd}-\mathrm{Sm}$, and the dark grey phase consists of $\mathrm{Mg}-\mathrm{Nd}-\mathrm{Gd}-\mathrm{Zn}-\mathrm{Sm}$, which formed as a third phase of the alloy. 
(a)

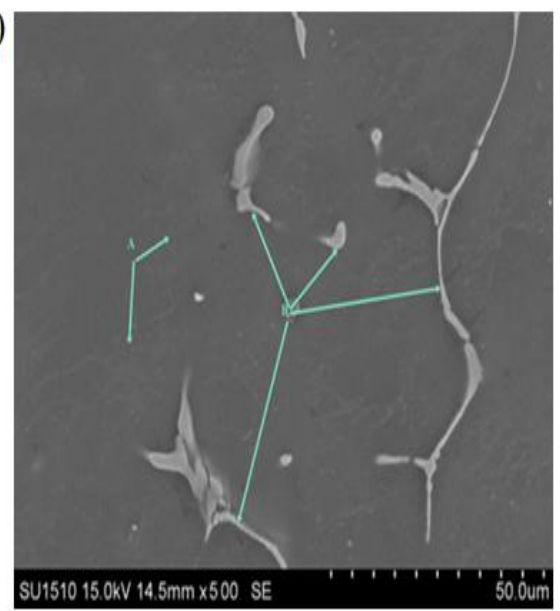

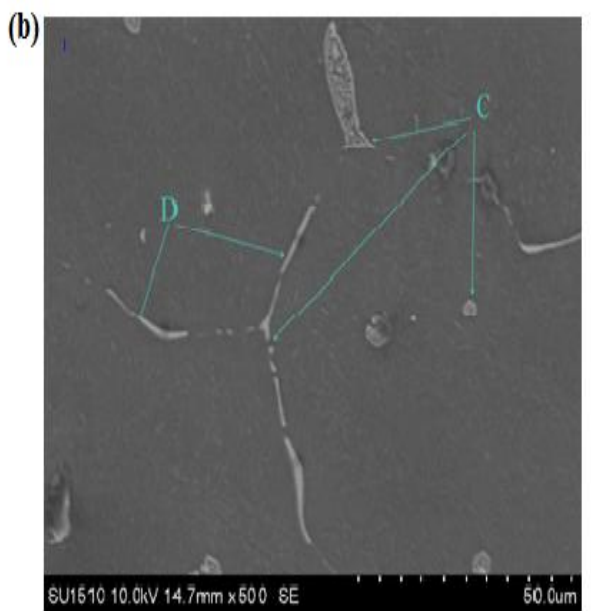

Figure 3. SEM micrographs (a) base alloy, (b) base alloy $+1.5 \mathrm{wt}$ \% Sm

SEM images also showed that the microstructure refined as addition of Sm and the grain boundaries become extremely distinct. In addition, the eutectic phase showed as a needle and granular morphology distributed randomly, Figure 3-b, and the granular compounds distributed into the $\alpha-\mathrm{Mg}$ matrix and the grain boundaries can restrain deformation of the matrix (Xu and Han 2012). Another researchers reported that the SEM micrographs of the as-cast $\mathrm{Mg}-6 \mathrm{Zn}-0.4 \mathrm{Zr}$ alloy and $\mathrm{Mg}-6 \mathrm{Zn}-4 \mathrm{Sm}-0.4 \mathrm{Zr}$ alloy consists of black $\alpha-\mathrm{Mg}$, grey eutectic phases distributed along grain boundaries and a few isolated particles inside the grains (Zhang, Huang et al. 2017).

Five phases are identified via XRD technique, which are $\alpha-\mathrm{Mg}, \mathrm{Mg} 12 \mathrm{Nd}, \mathrm{Zn} 2 \mathrm{Zr} 3, \mathrm{MgZn} 2$ and ternary phase (Mg3Zn6Sm) as shown in Figure 4. MgZn2 and Zn2Zr3 phases which have small amounts and dissolved inside the Mg matrix of base alloy, Zn2Zr3 has a tetragonal crystal structure and (a $3.3030 \AA$ - b $3.3030 \AA$ - c 11.2600 $\AA)$ as crystallographic parameters, while $\mathrm{MgZn} 2$ has a hexagonal crystal structure and crystallographic parameters (a $25.7760 \AA$ - b $25.7760 \AA$ - c $8.7620 \AA)$.

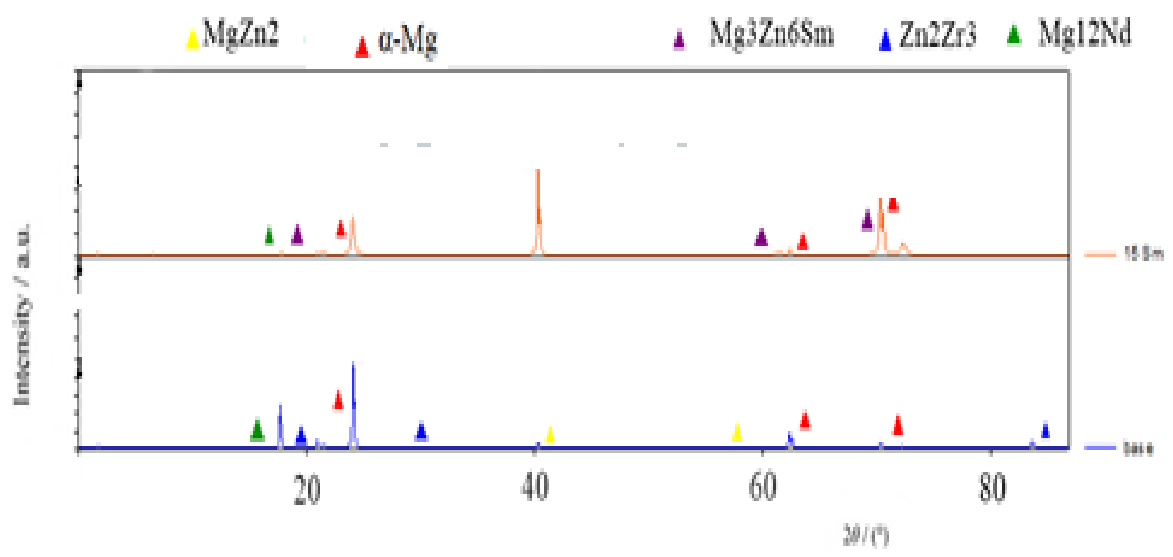

Figure 4. XRD patterns of $\mathrm{Mg}-\mathrm{Nd}-\mathrm{Gd}-\mathrm{Zn}-\mathrm{Zr}-1.5$ wt.\% Sm alloys

\subsection{Mechanical Properties}

As shown in Table 1, addition of Sm modified the values of Ultimate Tensile Strength(UTS).The UTS for base alloy with the value of $109 \mathrm{MPa}$. However, with $1.5 \mathrm{wt}$. \% Sm, the UTS increased sharply to $127.56 \mathrm{MPa}$. The results of this study are in good agreement with that obtained from the relationship between tensile properties and grain size of the Mg-6Zn-0.4Zr magnesium alloy (Zhang, Huang et al. 2017). The improvement in tensile properties is attributed mainly to refined grains and the formation of $\mathrm{Al}_{2} \mathrm{Sm}$ intermetallic compounds(Chen, Jin et al. 2015).

Table 1. Tensile strength results of base alloy and base alloys treated with $\mathrm{Sm}$

\begin{tabular}{|l|l|l|l|}
\hline Sm (wt.\%) & UTS (MPa) & YS (MPa) & EI (\%) \\
\hline
\end{tabular}




\begin{tabular}{|l|l|l|l|}
\hline 0 & 109 & 82.09 & 5.934 \\
\hline 1.5 & 127.56 & 97.6 & 8.176 \\
\hline
\end{tabular}

The YS increased sharply with the addition of $1.5 \mathrm{wt}$. \% Sm, obtaining 97.6 MPa compared to 82.09 MPa for the base alloy. The yield strength is dependent on RE content and increases with more RE, because of secondary and ternary phases that appears when RE add to magnesium alloy, which is due to decreasing of grain size. Sm rare earth element has a high solid solubility into the magnesium alloy, therefore, the solid solution strengthening has an important role in improving the mechanical properties of the Mg alloys treated with $\mathrm{Sm}$ ( $\mathrm{Li}$, Liu et al. 2014). Addition of Sm led tosharply increases the elongation (El) of alloy, which were 5.934 and $8.176 \%$ for 0 and1.5 wt.\% Sm respectively, which attributed to the effect of the formed intermetallic phases. Previous studies showed that the elongation of $\mathrm{Mg}$ alloys were increased as addition of Sm (ZHANG, HUANG et al. 2017), the intermetallic phases can provide very effective hindrances to grain boundary sliding and dislocation motion during deformation process, which leads to improved tensile properties (Sun, Hu et al. 2015 \& Hussain et al, 2020).

The hardness value increased with addition of Sm, which obtained $60.4 \mathrm{Hv}$ compared with $48.33 \mathrm{Hv}$ for the untreated alloy, the improvement in hardness attributed to the presence of comparatively harder $(\mathrm{Mg}-\mathrm{Zn}-\mathrm{RE})$ formed phases, as well as increasing its volume fraction. Moreover, the reduction in grain size (decremented by about $160 \mu \mathrm{m}$ ) as addition of Sm can also led to increase hardness value. It has been found that the addition of $\mathrm{Sm}$ to $\mathrm{Mg}$ alloys leads to increase hardness values with increasing Sm content due to the increase of volume fraction of the solute-rich precipitates (Xia, Sun et al. 2016). Moreover, Z, Y., et al. research concluded that the addition of Sm had a magnificent influence on the tensile properties and significant improvements of mechanical properties of magnesium alloy (ZHANG, HUANG et al. 2017).

\section{Conclusions}

The effects of added Sm on the solidification characteristics, microstructure, and mechanical properties of $\mathrm{Mg}-2.8$ wt. $\% \mathrm{Nd}-1.5$ wt. $\% \mathrm{Gd}-0.5$ wt. $\% \mathrm{Zn}-0.5$ wt. $\% \mathrm{Zr}$ magnesium alloy were investigated. The results are summarized as follows:

(i) The computer-aided cooling curve thermal analysis and microstructure results showed that Sm rare earth improve solidification time and grain refinement, where the grain size of treated alloy decreased by $160 \mu \mathrm{m}$ as decrease the solidification time by $47 \mathrm{~s}$.

(ii) SEM results showed that $\mathrm{Sm}$ combined with the initial phase of the intermetallic base alloy, which crystallized along the grain boundaries, and $\mathrm{M}_{\mathrm{g} 41} \mathrm{~S}_{\mathrm{m} 5}, \mathrm{M}_{\mathrm{g} 3} \mathrm{Z}_{\mathrm{n} 6} \mathrm{Sm}$ and $\left(\mathrm{Mg}, \mathrm{Zn}_{33} \mathrm{Sm}\right.$ were obtained as new phases.

(iii) The mechanical properties improved significantly as addition of Sm, were UTS and YS increased by 14.6 and $15.8 \%$ respectively as $\mathrm{Sm}$ content reached $1.5 \mathrm{wt}$. \%, furthermore, the hardness value improved greatly by $19.9 \%$ as well.

\section{Acknowledgements}

The authors would like to thank Universiti Tun Hussein Onn Malaysia (UTHM) for the financial support.

\section{References}

1. Ali, Y., et al. (2015). "Current research progress in grain refinement of cast magnesium alloys: A review article." Journal of Alloys and Compounds 619: 639-651.

2. Che, C., et al. (2017). "The Microstructures and Tensile Properties of As-Extruded Mg-4Sm-xZn-0.5 Zr $(\mathrm{x}=0,1,2,3,4 \mathrm{wt} \%)$ Alloys." Metals 7(7): 281.

3. Chen, Y. a., et al. (2015). "Effects of calcium, samarium addition on microstructure and mechanical properties of AZ61 magnesium alloy." Journal of Rare Earths 33(1): 86-92.

4. Dobrzański, L., et al. (2010). "Thermal analysis, structure and mechanical properties of the MC MgAl3Zn1 cast alloy." Journal of Achievements in Materials and Manufacturing Engineering 40(2): 167174.

5. Easton, M., et al. (2018). Development of Magnesium-Rare Earth Die-Casting Alloys. TMS Annual Meeting \& Exhibition, Springer.

6. Farahany, S., et al. (2012). "In-situ thermal analysis and macroscopical characterization of $\mathrm{Mg}-\mathrm{xCa}$ and $\mathrm{Mg}-0.5 \mathrm{Ca}-\mathrm{xZn}$ alloy systems." Thermochimica Acta 527: 180-189.

7. Ferro, R., et al. (2013). "Magnesium alloys of the rare earth metals: systematics and properties." Metallurgical Science and Tecnology 16(1). 
8. Guan, K., et al. (2018). "Effects of $1.5 \mathrm{wt} \%$ samarium (Sm) addition on microstructures and tensile properties of a Mg- 6.0 Zn- $0.5 \mathrm{Zr}$ alloy." Journal of Alloys and Compounds 735: 1737-1749.

9. Guan, K., et al. (2019). "Effects of samarium content on microstructure and mechanical properties of $\mathrm{Mg}-$ $0.5 \mathrm{Zn}-0.5 \mathrm{Zr}$ alloy." Journal of Materials Science \& Technology.

10. Guan, K., et al. (2017). "Microstructures and mechanical properties of a high-strength Mg-3.5 Sm-0.6 Zn0.5 Zr alloy." Materials Science and Engineering: A 703: 97-107.

11. Hussain, A., Manikanthan, S.V., Padmapriya, T., Nagalingam, M. (2020). Genetic algorithm based adaptive offloading for improving IoT device communication efficiency. Wireless Networks, 26 (4), pp. 2329-2338.

12. Li, H., et al. (2012). "Effect of $\mathrm{Zn} / \mathrm{Er}$ weight ratio on phase formation and mechanical properties of as-cast $\mathrm{Mg}-\mathrm{Zn}-\mathrm{Er}$ alloys." Materials \& Design 35: 259-265.

13. Li, Q. A., et al. (2014). Effects of Sm and Nd on microstructure and properties of AZ81 magnesium alloy. Advanced Materials Research, Trans Tech Publ.

14. Lotfabadi, A. F., et al. (2013). "Thermal characteristics and corrosion behaviour of Mg-xZn alloys for biomedical applications." Bulletin of Materials Science 36(6): 1103-1113.

15. Singh, L. K., et al. (2014). "The Effect of Yttrium Addition on the Microstructure and Mechanical Properties of Mg Alloys." Transactions of the Indian Institute of Metals 68(3): 331-339.

16. Song, P., et al. (2014). "Influence of cooling rate on solidification behavior of sand-cast Mg-10Gd-3Y$0.4 \mathrm{Zr}$ alloy." Transactions of Nonferrous Metals Society of China 24(11): 3413-3420.

17. Song, P., et al. (2015). "Influence of pouring temperature on solidification behavior, microstructure and mechanical properties of sand-cast Mg-10Gd-3Y-0.4 Zr alloy." Transactions of Nonferrous Metals Society of China 25(2): 363-374.

18. Sun, M., et al. (2015). "Effects of Sm on the grain refinement, microstructures and mechanical properties of AZ31 magnesium alloy." Materials Science and Engineering: A 620: 89-96.

19. Xia, X., et al. (2016). "Precipitation evolution and hardening in MgSmZnZr alloys." Acta Materialia 111: 335-347.

20. $\mathrm{Xu}, \mathrm{D} . \mathrm{K}$. and E. H. Han (2012). "Effects of icosahedral phase formation on the microstructure and mechanical improvement of Mg alloys: A review." Progress in Natural Science: Materials International 22(5): 364-385.

21. Xu, Z. C., et al. (2017). "Effects of Sm and Zr Addition on the Microstructure and Mechanical Properties in Mg-Cu Alloys." Key Engineering Materials 727: 88-92.

22. Zhang, D., et al. (2017). "Effects of substitution of $\mathrm{Nd}$ in a sand-cast Mg-2.5 Nd-0.6 Zn-0.5 Zr alloy with x wt.\% Sm (x=2.5, 4, and 6)." Journal of Rare Earths 35(12): 1261-1267.

23. Zhang, Y., et al. (2017). "Effects of Sm addition on microstructural evolution of Mg-6Zn-0.4Zr alloy during semi-solid isothermal heat treatment." China Foundry 14(2): 85-92.

24. ZHANG, Y., et al. (2017). "Effects of samarium addition on as-cast microstructure, grain refinement and mechanical properties of Mg-6Zn-0.4 Zr magnesium alloy." Journal of Rare Earths 35(5): 494-502.

25. Zhou, Y., et al. (2015). Microstructure and Mechanical Properties of Mg-12Gd-2Y-1Sm-0.5 Zr Alloy. 2015 International Conference on Materials, Environmental and Biological Engineering, Atlantis Press. 